\title{
Postpartum pituitary apoplexy with isolated oculomotor nerve palsy: A rare medical emergency
}

\author{
Sujeet Raina, Vaneet Jearth, Ashish Sharma ${ }^{1}$, Rajesh Sharma, Kewal Mistry ${ }^{2}$ \\ Departments of Medicine, ${ }^{1}$ Neurology and ${ }^{2}$ Radiodiagnosis, Dr. RPGMC, Tanda, Kangra, Himachal Pradesh, India
}

\section{ABSTRACT}

Pituitary apoplexy is a clinical syndrome characterized by sudden onset headache, visual deficits, ophthalmoplegia, altered mental status, and hormonal dysfunction due to an expanding mass within the sella turcica resulting from hemorrhage or infarction of pituitary gland. We report a case of pituitary apoplexy that developed in postpartum period following postpartum hemorrhage and presented with isolated third cranial nerve palsy.

Key words: Pituitary apoplexy, postpartum, oculomotor nerve

\section{Introduction}

Pituitary apoplexy is a medical emergency that occurs due to acute infarction or hemorrhage of the pituitary gland. Commonly, the event is a manifestation of an underlying pituitary adenoma. However, it may also occur in nonadenomatous or the normal pituitary gland. ${ }^{[1]}$ Postpartum hypopituitarism due to pituitary necrosis secondary to postpartum hemorrhage (Sheehan's syndrome) is an established entity. However, postpartum state is not a precipitating risk factor for hemorrhagic pituitary apoplexy. Isolated third nerve palsy is a rare manifestation of pituitary apoplexy. ${ }^{[2]}$ We report this case for three reasons. First, pituitary apoplexy presented in the postpartum state following postpartum hemorrhage in a nonadenomatous pituitary gland. Secondly, it manifested as isolated third cranial nerve palsy. Thirdly, the patient was managed conservatively with good outcome.

A 27-year-old, previously healthy female, gravida two presented herself in emergency with a history of

\section{Address for correspondence:}

Dr. Sujeet Raina, C-15, Type-V Quarters, Dr. RPGMC

Campus, Tanda, Kangra - 176 001, Himachal Pradesh, India.

E-mail: sujeetrashmishera@yahoo.co.in

\begin{tabular}{|l|l|}
\hline \multicolumn{2}{|c|}{ Access this article online } \\
\hline Quick Response Code: & Website: \\
\hline & www.ruralneuropractice.com \\
\cline { 2 - 2 } & \\
\hline & \\
\hline
\end{tabular}

postpartum hemorrhage following full term home conducted vaginal delivery in a rural town of Himachal Pradesh. At the time of admission, the patient was pale. Pulse was $110 / \mathrm{min}$, and blood pressure recorded was $110 / 80 \mathrm{mmHg}$. Further physical examination was normal. Her hemoglobin level was $4 \mathrm{~g} / \mathrm{dl}$. The patient was managed for postpartum hemorrhage and treated with three units of packed red blood cell transfusions. Her symptoms improved after blood transfusions. On the $2^{\text {nd }}$ day of admission, she complained of blurring of vision with headache and diplopia. Neurological examination was unremarkable on that day but on $3^{\text {rd }}$ day, headache persisted and drooping of right eyelid was complained. On examination, ptosis was present on right side. No periorbital swelling was observed. Restriction of medial/upward movement of right eye was observed. Pupils were bilateral equal and normally reacting to light. Perimetry was normal. The rest of the neurological examination and review of other systems were normal. Biochemical investigations including coagulation profile were normal. Cranial computed tomography was done which was normal. Magnetic resonance imaging (MRI) established diagnosis of pituitary apoplexy due to acute hemorrhage. MRI showed enlarged pituitary gland with hypointense signal on T2-weighted (T2W), iso- to hyper-intense signal on T1-weighted (T1W) images

This is an open access article distributed under the terms of the Creative Commons Attribution-NonCommercial-ShareAlike 3.0 License, which allows others to remix, tweak, and build upon the work non-commercially, as long as the author is credited and the new creations are licensed under the identical terms.

For reprints contact: reprints@medknow.com

How to cite this article: Raina S, Jearth V, Sharma A, Sharma R, Mistry K. Postpartum pituitary apoplexy with isolated oculomotor nerve palsy: A rare medical emergency. J Neurosci Rural Pract 2015;6:598-600. 
and peripheral enhancement on gadolinium-enhanced fat saturated T1W image [Figure 1]. The patient was started on hydrocortisone $100 \mathrm{mg}$ IM bolus followed by $50 \mathrm{mg} 6$ hourly by intramuscular injection. Her investigations were: T3-53.22 (reference range 58-159 $\mathrm{ng} / \mathrm{dl}$ ); T4-4.77 (reference range $4.87-11.71 \mu \mathrm{g} / \mathrm{dl})$; thyroid stimulating hormone-1.33 (reference range 0.35-4.94 $\mu \mathrm{IU} / \mathrm{ml}$ ); luteinizing hormone-0.24 (reference range 1.1-11.6 mIU// $\mathrm{ml}$ ); follicle stimulating hormone-1.06 (reference range 2.8-11.3 $\mathrm{mIU} / \mathrm{ml}$ ); prolactin-121.7 (reference range $5.18-26.53 \mathrm{ng} / \mathrm{ml}$ ), and cortisol-12 $\mu \mathrm{g} / \mathrm{dl}$ (reference range $5-25 \mu \mathrm{g} / \mathrm{dl}$ ). The patient was also started on thyroid hormone replacement therapy along with oral hydrocortisone. By $12^{\text {th }}$ day, patient completely recovered with no residual deficit. During follow-up, her blood pressure is normal, she is maintaining her weight, her blood glucose and serum electrolytes are normal and thyroid functions normalized. Follow-up imaging 3 months later showed resolved bleeding and did not reveal any pituitary adenoma [Figure 2].

\section{Discussion}

During pregnancy, the pituitary gland is one of the most affected organs with altered anatomy and physiology. The pituitary gland is enlarged as a result of lactotroph hyperplasia during pregnancy and postpartum period. The highest pituitary volumes and widths of the infundibulum have been observed during the first 3 postpartum days that are significantly higher than that

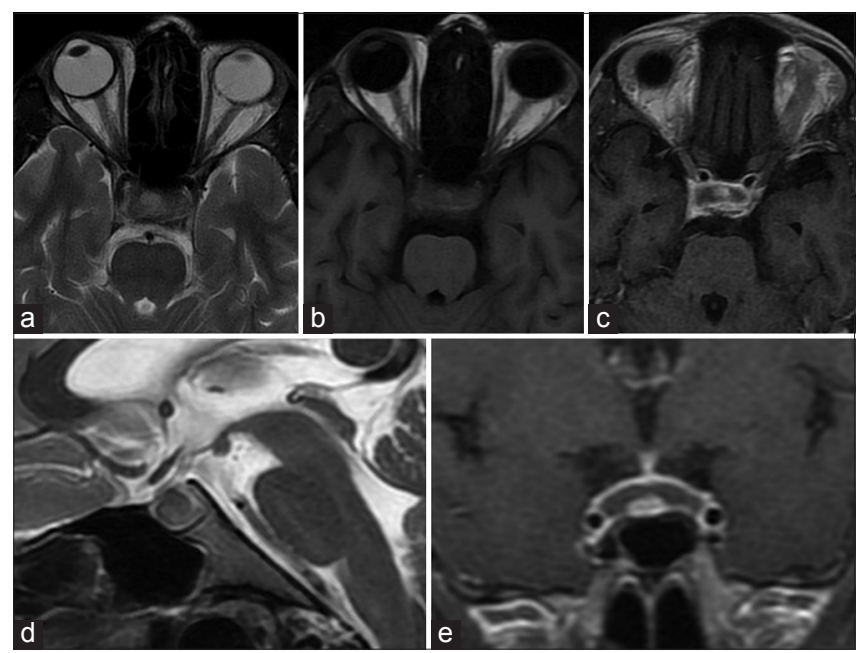

Figure 1: Axial magnetic resonance images from initial scan done show enlarged pituitary gland with hypointense signal on T2-weighted (a) iso- to hyper-intense signal on T1-weighted images (b) and peripheral enhancement on gadolinium-enhanced fat saturated T1-weighted image (c) consistent with acute bleed. Sagittal T2-weighted (d) and coronal gadolinium-enhanced fat saturated T1-weighted images (e) show enlarged pituitary gland $(12.5 \mathrm{~mm}$ in height) during the last half of pregnancy. The pituitary gland gains their normal size, shape, and volume within 6 months postpartum. ${ }^{[3,4]}$ The clinical syndrome of pituitary apoplexy is rare and is often misdiagnosed because of its highly variable clinical presentation. ${ }^{[5]}$ The diagnosis of pituitary apoplexy is often delayed as more than $80 \%$ of these patients will have no previous history of a pituitary problem and the clinical features mimic other more common neurological conditions. Ocular palsies, most commonly a third nerve palsy, can occur due to the involvement of the cavernous sinus. Reduced visual acuity and visual field defects, most commonly a bi-temporal hemianopia, are due to optic chiasmal compression. Fever, neck stiffness, photophobia, or reduced consciousness may occur. Although pituitary apoplexy can occur without any precipitating factor in most cases, there are some well recognizable risk factors such as hypertension, medications, major surgeries, coagulopathies either primary or following medications or infection, head injury, radiation or dynamic testing of the pituitary. ${ }^{[1]}$ The MRI findings in the acute phase (0-7 days) are hypointense on $\mathrm{T} 2 \mathrm{~W}$ imaging with isointensity or slight hypointensity on $\mathrm{T} 1 \mathrm{~W}$ imaging. In the subacute phase (7-21 days), the hemorrhage will appear hyperintense on T1WI as well as on T2WI. In the chronic phase ( $>21$ days), strong hypointensity on both T1WI and T2WI is observed. ${ }^{[6]}$

Postpartum state is an uncommon precipitating factor and risk factor for pituitary apoplexy. The mechanism of hemorrhage in the nonadenomatous pituitary following postpartum hemorrhage is difficult to explain. The proposed explanation is that postpartum hemorrhage has triggered changes in the vascular supply of enlarged pituitary glands, thereby producing an ischemic necrosis followed by hemorrhage as a secondary occurrence.
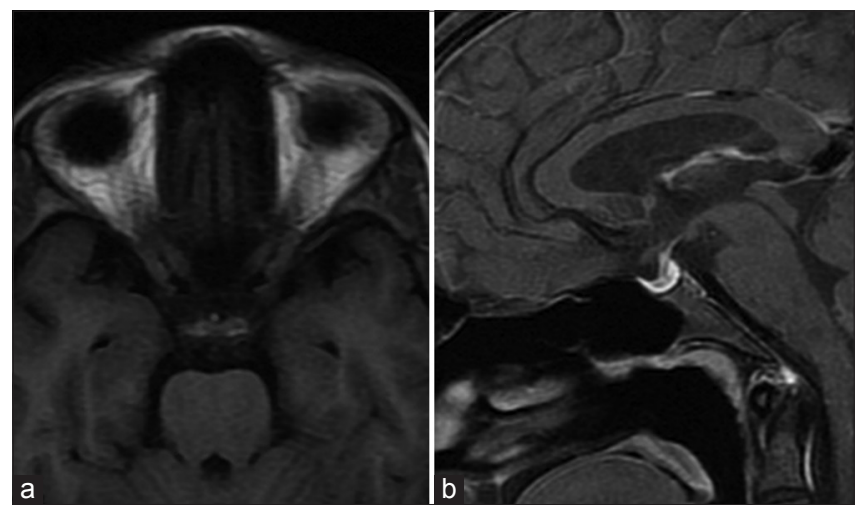

Figure 2: Magnetic resonance images from follow-up scan (3 months after initial scan). Axial T1-weighted (a) and sagittal gadoliniumenhanced fat saturated T1-weighted images (b) show resolution of the bleed with small sized ( $4 \mathrm{~mm}$ in height) relatively homogenously enhancing residual pituitary gland 
This hypothesis has been proposed by other authors in the literature also. ${ }^{[5]}$ In the present case, considering the findings of MRI and her acute presentation followed by full recovery on medical management, the most likely explanation for the isolated oculomotor nerve palsy is the direct compression of the cavernous sinus by sudden secondary expansion caused by pituitary apoplexy with subsequent compression or infarction of the nerve. Previous reports of sudden-onset third cranial nerve palsy have been attributed to the compromise of the vascular supply to the nerve due to compression of the vasa nervorum originating in the internal carotid artery and a large pituitary mass compressing upon the third cranial nerve within the lateral wall of the cavernous sinus. ${ }^{[2]}$

Acute pituitary apoplexy is unpredictable and should be considered in any patient with abrupt endo-neuro-ophthalmological deterioration. A high index of clinical suspicion is essential to diagnose this condition particularly in a setting where patient does not have any pituitary related signs and symptoms in past. Prompt conservative management without surgery may be life-saving. This is because acute secondary adrenal insufficiency is seen in approximately two-thirds of patients with pituitary tumor apoplexy and is an important cause of mortality associated with the condition. ${ }^{[1]}$

\section{Financial support and sponsorship}

Nil.

\section{Conflicts of interest}

There are no conflicts of interest.

\section{References}

1. Ranabir S, Baruah MP. Pituitary apoplexy. Indian J Endocrinol Metab 2011;15 Suppl 3:S188-96.

2. Cho WJ, Joo SP, Kim TS, Seo BR. Pituitary apoplexy presenting as isolated third cranial nerve palsy with ptosis: Two case reports. J Korean Neurosurg Soc 2009;45:118-21.

3. Dinç H, Esen F, Demirci A, Sari A, Resit Gümele H. Pituitary dimensions and volume measurements in pregnancy and post partum. MR assessment. Acta Radiol 1998;39:64-9.

4. Elster AD, Sanders TG, Vines FS, Chen MY. Size and shape of the pituitary gland during pregnancy and post partum: Measurement with MR imaging. Radiology 1991;181:531-5.

5. Biousse V, Newman NJ, Oyesiku NM. Precipitating factors in pituitary apoplexy. J Neurol Neurosurg Psychiatry 2001;71:542-5.

6. Boellis A, di Napoli A, Romano A, Bozzao A. Pituitary apoplexy: An update on clinical and imaging features. Insights Imaging 2014;5:753-62. 